Anke Büter

\title{
Social Objectivity and the Problem of Local Epistemologies
}

\begin{abstract}
The value-freedom of scientific knowledge is commonly hold to be a necessary condition for objectivity. Helen Longino's contextual empiricism aims to overcome this connection. She questions the suitability of the normative ideal of value-freedom and develops an alternative conception of objectivity, which integrates social and epistemic aspects of scientific enquiry. The function of this notion of 'social objectivity' is to make value-laden assumptions assessable through a process of criticism, even if there cannot be any guarantee of their elimination. This assessability requires common standards of evaluation, which are threatened by Longino's rejection of the distinction between cognitive and non-cognitive values guiding theory choice. I will argue that in order to resolve this inherent tension, social objectivity has to be understood as based on a procedural epistemology and, differing from Longino's own approach, must include the normative requirement to strive for consensus instead of allowing for epistemological pluralism.
\end{abstract}

\section{Introduction}

The value-freedom of science has traditionally been considered a necessary condition for its objectivity, while objectivity lies at the core of science's claim to epistemic integrity as well as authority compared with other modes of beliefproduction. 'Objectivity' here roughly refers either to the results or the processes of producing beliefs about the natural world that are determined by impartial and non-arbitrary criteria. Accordingly, the elimination of subjective influences such as values from the justification of scientific contents is often seen as essential for what bestows worthiness on the endeavor of science in the first place.

Value-freedom has however been thoroughly questioned in the last decades. On the one hand, its philosophical soundness is challenged by underdetermination arguments; on the other hand, work in the history and sociology of science casts doubts on the value-freedom of much actual science. Today, it is widely accepted that value-freedom understood as an empirical thesis about science is often problematic. But while it is granted that not all science is value-free, the idea that it ought to be (as value-free as possible) is often held on to. Given its supposed relation to the notion of scientific objectivity, this perseverance is unsurprising. Following this line of reasoning, the regulative function of value- 
freedom understood as a normative ideal is what prevents science from collapsing into politics or religion, and the degree of its realisation therefore serves as a criterion of epistemic quality.

Related debates about science and values used to be characterized by a strong opposition between philosophical and sociological (especially social constructivist) approaches. The former tried to exclude social and especially value-laden influences from the justification of scientific contents, adhering to rather strict conceptions of objectivity and scientific rationality; the latter argued on an empirical basis for the ubiquity of such influences and inferred an illegitimacy of the scientific claim to objectivity. This opposition of sociological versus philosophical accounts has proven infertile in so far as the social 'overdetermination' seems to be an account of scientific practice at least as implausible as any epistemological 'overidealisation'. Dissatisfaction with this dichotomy constitutes one of the starting points of social epistemology, which aims to explain how scientific knowledge is produced in a social framework without loosing its epistemic integrity.

Here, I will discuss one of the most influential as well as controversial accounts in this field: Helen Longino's contextual empiricism. Longino not only criticizes the ideal of value-freedom but also develops a normative alternative called 'social value management', which is based on a reconceptualisation of 'objectivity' as inherently social. ${ }^{1}$ The thesis I want to bring forward is that social objectivity provides a valuable notion, yet exhibits a lack of soundness in connection with Longino's insistence on the mere local reach of normative epistemological claims. In what follows, I will first introduce contextual empiricism and the concept of social objectivity, and proceed to highlight that Longino's contextualist approach differs from a relativistic one by the central role it ascribes to shared standards of theory assessment. I will then explain how these standards are threatened by her rejection of the distinction between cognitive and non-cognitive values guiding theory choice decisions. Concerning this problem, I will argue that the assumed lack of any absolute, fixed standards of theory assessment does not necessitate an epistemological pluralism or the rejection of non-empirical standards as being merely of heuristic nature, as Longino's work suggests. Rather, this lack calls for an epistemology that is procedural on multiple levels, which must moreover include the normative requirement of a strive for consensus on appropriate goals, standards, and contents - even if there is no Archimedean point this striving could be based upon.

\footnotetext{
1 Another account important to mention in this respect is Philip Kitcher's ideal of "wellordered science" (cf. Kitcher 2001). Well-ordered science is a science that is socially responsible and democratic regarding the direction of research. Here, decisions on the choice of research problems are ideally made by representatives of different societal groups, who are tutored by impartial scientific experts. Since Kitcher largely holds on to the connection of the valuefreedom of justification and objectivity described above, I will concentrate on Longino's more radical proposal. In contrast to her social value management, well-ordered science does not aim to replace the ideal of value-free science, but rather supplements it by an external democratisation of the 'context of discovery'.
} 


\section{Contextual Empiricism and Social Objectivity}

Helen Longino's critical contextual empiricism rejects the ideal of value-free science and the related understanding of objectivity as the production of impartial knowledge. Her starting point is an underdetermination thesis concerning evidential relations. ${ }^{2}$ Following Longino, the relevance of data to the assessment of a theoretical hypothesis is not given by the data as such but presumes their interpretation in the light of beliefs about the examined state of affairs and its connections with others. The relation between theoretical hypotheses and empirical consequences is not one of logical entailment, but underdetermined and mediated by background assumptions. These background assumptions can be of methodological as well as of substantial nature, and include for example suppositions about the ontological structure or the relevant causal relations to be found in a research field. Crucial here is that according to Longino, these background assumptions are possibly value-laden (cf. Longino 1990, 40-48).

A prominent example stems from evolutionary anthropology, where fossils of bones, footprints, or tools (besides questionable analogies with contemporary primates or gatherer-hunter-peoples) provide an empirical basis utilized to support contrasting hypotheses. The 'man-the-hunter'-model relates the use of tools to the activity of hunting, thereby signifying a traditionally male activity as the decisive promoter of human evolutionary progress. In the 1970s, female scientists entering the field developed the 'women-the-gatherer'-model, which traces the usage of tools back to activities like gathering, digging, and preparing food, i.e. to a domain traditionally perceived as female. The given empirical evidence is insufficient to choose between those alternative accounts, and it seems plausible that the ascription of tool usage to a presumably male domain is supported by value-laden background assumptions, which are not shared by the opposite side. It moreover seems suspicious that both models conform to contemporary gender role conventions (cf. 106-111).

In this case, the same empirical data are utilized to support contrasting hypotheses (informed by directly opposed values). Another possibility is that incompatible theories are each supported by empirical evidence, but are not empirically equivalent (i.e., the supporting data differ in these cases). An example is provided by Longino's detailed case study of research on gender-specific behaviour. She distinguishes two explanatory models applied in the concern-

\footnotetext{
2 To put it very briefly, the Duhem-Quine-thesis of underdetermination states that theories are underdetermined by logic and evidence, i.e. that decisions about the acceptance or rejection of theories cannot be ascertained on their grounds alone. The thesis presumes the hypotheticodeductive model of research, in which theoretical hypotheses are tested via their empirical consequences. This empirical test does not have unequivocal consequences for the validation of the concerned hypothesis because the inference to a particular empirical consequence requests further hypotheses, for example background knowledge about the subject-matter or the used devices. Therefore, even negative empirical results may not falsify a given hypothesis; they just indicate that there is some mistake in the concerned net of hypotheses, but cannot single out the responsible one. Nor can hypotheses be definitely verified; even if their empirical consequences are validated, it is impossible to exclude that alternative hypotheses would be equally supported by the evidence. Thus, hypothetico-deductive testing can neither falsify nor verify theories with certainty.
} 
ing studies: the 'linear-hormonal model' and the 'selectionist model'. The first is based on evidence of correlations between behaviour and prenatal hormone levels, and interprets this relation as a causal one between hormones and neuro-physiological development (in turn leading to behavioural differences). By contrast, the latter postulates a permanent (postnatal) adjustment of neuronal structures to environmental influences, thus making gender-specific life experiences an integral part of the biological explanation of respective behaviour. This approach can build on empirical evidence of correlations between environment and behaviour, and it questions the uni-directional interpretation of correlations between biological sex and social gender. As Longino states, both models can be seen as empirically supported by the data considered most significant, but there is no conclusive evidence to choose one above the other. Instead, the support of one of these models can be promoted by values, as she argues: while the linear model presumes dimorphism (or sexual essentialism), i.e. the idea of a relevant difference between male and female behaviours to be explained biologically, the selectionist model does not. Obviously, the adoption of this dimorphistic background assumption could have significant social consequences by supporting the view that there are sex-appropriate and sex-inappropriate behaviours based on biological factors (cf. 112-161). ${ }^{3}$

It is however important to see that Longino does not argue that all science is necessarily value-laden (as, for example, Ruphy 2006 reads her to), only that there is always a possibility (in some fields greater than in others) of valueinfluences via background assumptions due to the gap between theory and evidence:

"One of the main lessons of the underdetermination argument is that there are no formal rules, guidelines, or processes that can guarantee that social values will not permeate evidential relations. If this is so, then it is a contingent matter whether a given theory produced according to the best rules is value-laden or not." (Longino 2002, 50)

For her, this possibility does not lead to a rejection of scientific claims to objectivity, but rather calls for a rethinking of objectivity that integrates the role of background assumptions. Longino considers the latter as possibly identifiable by a process of mutual criticism. This criticism enables the scientific community to discover value-influenced assumptions and to gradually screen them out.

\footnotetext{
3 The example from evolutionary anthropology might seem reconcilable with the ideal of value-free science by requiring that once the respective value-assumptions become clear, and the empirical evidence is inconclusive, researchers should just refrain from accepting one or the other model. The second example is intended to show that the situation is not that easy. The linear and the selectionist model differ essentially in what is regarded as the most significant evidence, this significance in turn being a function of the questions asked and the background assumptions at play. In this case where differing kinds of evidence are available, if the research presumes sexual essentialism and then proceeds to accumulate biological evidence for the related hypotheses, it is highly probable that this premise will in turn be reenforced. On the other side, by concentrating on environmental influences, hypotheses about the variable nature of behaviour and neurological structures are likely to gain empirical support. The body of accepted theories we end up with essentially depends on the framing of research, which might be value-laden (see also below).
} 
However, the criticism might itself be informed by values, as in the case of the 'woman-the-gatherer'-model:

\begin{abstract}
"It puts women at the center of the evolutionary story, but the women bear a remarkable kinship to contemporary stereotypes. While this framework is as gynecentric as its rival is androcentric, its great value from a logical point of view is its revelation of the epistemologically arbitrary character of the man-the-hunter framework." (Longino 1990, 130)
\end{abstract}

Due to this possibility, there can be no guarantee of the value-freedom of scientific contents. Longino's criticism of the ideal of value-freedom is compatible with the idea that value-free science can be good science; but the ideal is ill-suited to serve as the basis of scientific objectivity, since it is not operationalizable in a way that allows to identify when it is reached. Contextual empiricism by contrast does not primarily aim at the elimination of all value-influences, but at rendering them visible and assessable through a discussion by all members of the scientific community. Accordingly, Longino develops a new understanding of 'objectivity' as a gradual matter of criticism and thus as essentially social:

"It is the possibility of intersubjective criticism, at any rate, that permits objectivity in spite of the context dependence of evidential reasoning. [...] Objectivity, then, is a characteristic of a community's practice of science $[. ..] . "(71 ; 74)$

The social nature of science thereby becomes an epistemic resource and constitutes the very possibility of scientific objectivity. As a consequence of this, structures and institutions of the scientific community, which are supposed to promote the process of criticism, gain normative relevance. Longino names four community-related criteria for the evaluation of objectivity: the existence of recognized avenues for criticism (1), community response to this criticism (2), shared standards of theory assessment (3), and equality of intellectual authority of all qualified participants (4) (cf. 62-83).

The last condition of intellectual equality is important because Longino assumes that values are often taken for granted by those who hold them, which is why shared values of a scientific community will be hard to detect through mutual criticism. In connection with the plausible premise that a person's values correlate to a considerable extent with her socio-cultural background, this leads to a demand for the integration of diverse perspectives, i.e. participants of different social status, religion, gender, political orientation, etc., into the scientific community and the process of criticism. It is the interaction of participants with different values that is supposed to enable a community to make value-laden background assumptions visible. ${ }^{4}$

\footnotetext{
4 Just as Kitcher's well-ordered science, Longino's social value management thereby integrates democratic elements, but for her, this is not only a political desideratum, but an epistemic requirement.
} 


\section{Contextualism versus Relativism}

In order to highlight some important aspects of Longino's position, I think it is helpful to discuss as exemplary an article by Tara Smith, in which she criticizes the social account of objectivity for being relativistic:

"Essentially, what social objectivity delivers is merely a bridled relativism. At core, it is no more objective than the unbridled relativism that Longino wishes to avoid." (Smith 2004, 145)

This charge of relativism results from an understanding of Longino's view as a consensualist account, which invites the call for a standard external to a group's agreement in order to evaluate objectivity:

"Knowledge certainly does often benefit from the contributions of many people. It does not follow from this, however, that others' beliefs should become the standard of objective knowledge. Yet this is the implication of the social conception, which replaces the relevant reality as the arbiter of knowledge with a group's 'critical consensus'."

Contrary to Smith, the point of 'social objectivity' is not to replace reality with consensus, but rather the theory-ladenness and potential value-ladenness of any understanding and perception we can have of the world, which implies the impossibility to assign reality the role of an impartial touch-stone of scientific claims. Every achievable account will rest on some background assumptions, which mediate the relation between theory and empirical evidence. Since these assumptions might be value-laden and lead to systematically biased results due to individual or collective preferences, there is a need for a mechanism to check their influences. This is exactly what social objectivity wants to offer with its request for mutual criticism from different perspectives, which, according to Longino, will leave us with the best theories available: those scientific contents that have survived the thorough process of challenges from all possible sides. This does not require merely consensus as such, but a consensus arrived at while maintaining certain conditions. There must be established procedures and media for criticism (1), diverse perspectives must be considered (4), and every relevant criticism must be answered (2). Most crucially, the consensus in question is not just a resulting majority vote because the criticism and evaluation of theories must invoke public standards for theory acceptance (3). Thus, at least not every result is a possible candidate for consensus, and the group's agreement is not a sufficient condition. For the empiricist Longino, these public standards moreover contain as a necessary requirement the empirical adequacy of theories, which is why the allegation that "believing, like wishing, does not make things so" (Smith $2004,148)$ is not to the point.

In order to distinguish knowledge from (majority) opinion, Longino develops a notion of epistemic acceptability that combines social with empiricist requirements. While her conception of objectivity refers to the procedures of a scientific community, epistemic acceptability refers to the contents thereby produced: 
"Some content A is epistemically acceptable in community $\mathrm{C}$ at time $t$ if $\mathrm{A}$ is or is supported by data $d$ evident to $\mathrm{C}$ at $t$ in light of reasoning and background assumptions which have survived critical scrutiny from as many perspectives as are available to $\mathrm{C}$ at $t$, and $\mathrm{C}$ is characterized by venues for criticism, uptake of criticism, public standards, and tempered equality of intellectual authority." (Longino $2002,135)$

To count as knowledge, scientific contents must conform to the relevant data. Longino's criticism of the value-free ideal holds on to the minimal condition of not simply replacing the role of evidence by subjective preferences. But the selection and interpretation of data depends on background assumptions that might incorporate value-laden conceptions of the subject-matter. Therefore, epistemic acceptability of a hypothesis is not provided by its accordance with data alone, but requires in addition the hypothesis' exposure to every possible criticism of the community. To ensure the efficiency of this criticism, the community must meet the social conditions for objectivity.

\section{Public Standards and Theory Choice}

The role of background assumptions explains why accordance with data is necessary, but insufficient for the evaluation of theories. For Longino, the gap opened by underdetermination is closed through the process of mutual criticism that makes value assumptions assessable. Yet, Smith has an important point in her call for external criteria, which are supposed to inhibit a closure of the gap by means of value-conform choices among empirically adequate alternatives. Therefore, the existence of shared standards for theory assessment (3) is at the core of a socialised understanding of objectivity, if it is to function as a condition for the epistemic acceptability of scientific contents. Since the process of criticism is to result not only in consensus, but in a somehow justified and epistemically trustworthy consensus - and empirical adequacy alone is insufficient in this respect - this criticism must proceed on the basis of other, non-empirical criteria of epistemic acceptability.

The discussion of such non-empirical criteria traditionally proceeds under the label of epistemic values in theory choice. The problem of theory choice is generated by the possibility of different theories each compatible with the data, but incompatible with each other. ${ }^{5}$ Thomas Kuhn was the first to refer to the criteria in question as 'values' on grounds of their function: they guide theory choice decisions, but they cannot fully determine them. They do not constitute rules that are algorithmically applied, but allow for various choices. He identifies the following values as shared criteria ${ }^{6}$ for good theories: empirical adequacy,

\footnotetext{
5 These alternatives do not have to be completely empirically equivalent, but might each have their merits and flaws in different respects that must be weighted against one another.

6 The terminology might look a bit confused here. I understand 'values' as properties of an entity $x$ which deem to be constitutive of a 'good' $x$ (cf. Laudan 2004, 19). Here, the relevant entities are specified as theories (or other forms of scientific contents, e.g. models); hence, the
} 
internal and external coherence, scope, simplicity, and fruitfulness. Empirical adequacy means accordance of a theory's empirical consequences with the relevant experiments and observations. This and the internal consistency of a theory are the only necessary criteria. Others are external coherence, i.e. coherence with other approved theories of the field; breadth of scope, meaning that the consequences of a theory should exceed those phenomena it was originally designed to explain; simplicity, which denotes the unification of otherwise isolated results; and finally fruitfulness, which refers to the generation of new research results (cf. Kuhn 1977, 321ff.). ${ }^{7}$

According to Kuhn, scientific practice displays these values as shared standards of theory assessment. However, firstly they are rather abstract, secondly they are often not simultaneously maximally satisfiable and do not imply any hierarchical ordering (cf. Longino 1995, 390). It follows that in any specific situation of theory choice, they have to be interpreted as well as weighted, so that, with reference to the same criteria, different people can reach contrasting conclusions about which theory to choose. On the one hand, this leads to 'Kuhn-underdetermination'- the possibility of other (e.g. social) values influencing the application of the listed values for theory choice decisions (cf. Carrier 2008, 276ff.). ${ }^{8}$ On the other hand, this facilitates conceiving of scientific dissent as rational. This dissent plays a central role for the progress of science, as Kuhn states: only the ambiguity of choices can guarantee a broad spreading of scientists' efforts and an indispensable distribution of risks (cf. Kuhn 1977, 333f.).

Ernan McMullin follows Kuhn in regarding theory choice decisions as being guided by values, since there is no determining algorithm. He coins the expression 'epistemic values' for the Kuhnian list of shared criteria, thereby starting the still ongoing debate on how to distinguish epistemic from non-epistemic values. McMullin considers these values as embedded in scientific practice, too. According to him, they result from a learning process as to which properties of a theory enhance its truth-probability:

"Even though we cannot definitely establish the values appropriate to the assessment of theory, we saw just a moment ago that we can provide a tentative list of criteria that have gradually been shaped over the experience of many centuries, the values that are implicit

values in question are properties of good theories and as such, their realisation can serve as a criterion of epistemic quality. 'Criteria' and 'standards' I will use synonymously.

7 Besides this list, there are of course others which add criteria or interpret them differently; here, I will however concentrate on Kuhn's classic enumeration.

8 Carrier identifies an important function of meta-methodological theories here, namely to provide a more systematic basis of non-empirical values, which can guide their interpretation and weighting. For example, Larry Laudan considers 'problem-solving' the goal of science; accordingly, theories are evaluated in respect of the number and rate of growth of problem solutions. Falsificationist positions make testability a central criterion. Imre Lakatos proposes to evaluate the progressiveness of research programmes and considers the prediction of new phenomena as decisive. This list could be continued; it shows the possibility of good reasons for non-empirical standards, but at the same time illustrates that the establishment of one general and ultimate canon and ranking of values for theory choice decisions is utterly problematic. Thus, the possibility of Kuhn-underdetermination cannot be ruled out so far (cf. 284ff.). 
in contemporary scientific practice. Such characteristic values I will call epistemic, because they are presumed to promote the truth-like character of science, its character as the most secure knowledge available to us of the world we seek to understand. An epistemic value is one we have reason to believe will, if pursued, help toward the attainment of such knowledge." (McMullin 1983, 18)

Kuhn-underdetermination also allows for other values to enter theory choice decisions, for example political, social, moral, or religious values, which are subsumed under the term 'non-epistemic' by McMullin. Nevertheless, these non-epistemic values are supposed to be eliminated as the process of hypotheses testing and probation continues:

"To the extent that non-epistemic values and other non-epistemic factors have been instrumental in the original theory decision [...], they are gradually sifted out by the continued application of the sort of value-judgement we have been describing here. The non-epistemic, by very definition, will not in the long run survive this process." (23)

By distinguishing epistemic from non-epistemic values, McMullin tries to restore scientific value-freedom on another level: values do play a decisive role, but only certain 'scientific' values. Whether a value can be classified as epistemic or not is, according to him, a question of its contribution to the goal of science-which for him lies in the attainment of truths - and of the availability of good reasons to assume such a contribution. The questionable good reasons must thus explicate why a certain value enhances the truth-likeliness of a theory. Yet such a relation of the epistemic values and truth is difficult to establish.

On the one hand, there are systematic reasons for this difficulty. First of all, an empirical answer to the question of whether certain values enhance truthlikeliness would presume the possibility of comparing the truth degrees of different theories. Since the problem only arises on the assumption of competing theories each empirically adequate, we would need additional non-empirical criteria to evaluate their truth-which is exactly what is in question. Second, there is no logical or analytic connection between the notions of truth and the epistemic values. As Larry Laudan puts it: "None of these rules [epistemic values] can have an epistemic rationale since it is neither necessary nor sufficient for the truth of a statement that it exhibits any of these attributes." (Laudan 2004, 16) The history of science displays numerous examples of once accepted theories that exhibited the relevant traits, but later were rejected in light of a new, incompatible candidate. Then again one can easily imagine truths that are nothing but (sets of) trivial propositions and display none of the presumably epistemic values.

On the other hand, there are good reasons to doubt the truth-enhancing character of the proposed values. External coherence as an indicator of truth depends on the presumed truth of other accepted theories in the research field and can therefore not provide any independent support of the relation in question. Regarding simplicity and breadth of scope, interpreted as a demand for 
parsimony either with respect to ontologies or explanations, these values might indeed conflict with requests for empirical accuracy - which can be seen as argument against an enhancement of truth by them (cf. for example Longino 2008, $72-74)$. Fruitfulness at last is often seen as a rather pragmatic criterion. ${ }^{9}$

Because of these difficulties to establish the relation to truth, Laudan replaces the 'epistemic'-distinction by one between 'cognitive' and 'non-cognitive' values, the former being defined as constitutive of good (not true) theories or science: "An attribute will count as a cognitive value or aim if that attribute represents a property of theories which deem to be constitutive of 'good science'." (Laudan 2004, 19) By denying the Kuhnian values the status of 'epistemic', it is by no means said that they cannot provide criteria for the quality of theories. It makes it however impossible to distinguish legitimate from illegitimate values in theory choice based on a contribution to the truth of those theories. This reopens the question of whether the value-free ideal can be saved as one of 'scientific values only'.

\section{Longino's Feminist Values}

Longino famously attacks the possibility of a clear separation of cognitive (legitimate) and non-cognitive (illegitimate) values, thereby denying a modified ideal of value-free science that allows of cognitive values only. She adopts the argumentative strategy of making the relevance of values to theory choice decisions depend on the goals of science, but in contrast to McMullin, she does not propose any absolute goal like truth. ${ }^{10}$ Rather, she suggests a plurality of (possibly conflicting) goals of specific research programmes:

"Truth simpliciter cannot be such a goal, since it is not sufficient to direct enquiry. Rather, communities seek particular kinds of truths. They seek representations, explanations, technological recipes, and so on. Researchers in biological communities seek truths about the development of individual organisms, about the history of lineages, about the physiological functioning of organisms, about the mechanics of parts of organisms, about molecular interactions, and so on." (Longino 2008, 80)

She replaces the cognitive/non-cognitive distinction with one between constitutive and contextual values, those values being constitutive that promote the actual research goals (cf. Longino 1990, 4f.). The distinction of contextual and constitutive values is therewith itself not an absolute one, but depends on the

\footnotetext{
9 Another possibility is to understand fruitfulness as promoting falsifiability by generating empirical consequences. In general, a lot depends on the exact interpretation of the Kuhnian values and the rationales given for those interpretations. I will not provide a detailed discussion of the numerous possibilities here, since I pursue only the moderate aim to plausibilise Longino's rejection of a relation of the discussed values to the truth of theories. The burden of proof seems to lie on the other side.

10 On the difficulty to establish one goal of science, cf. also Kitcher 2001, chapter 6.
} 
context of individual research programmes and the goals they pursue. The same values can therefore function as constitutive or contextual in different situations.

In order to support her criticism of an absolute distinction between cognitive and non-cognitive values, Longino develops an alternative list of values relevant to theory choice decisions. This list contains empirical adequacy, internal consistency, novelty, ontological heterogeneity, complexity of relation, applicability to human needs, and diffusion of power. She generates this list from case studies of research that pursues feminist objectives and contrasts it with Kuhn's. An important point to stress here is that these feminist objectives also represent cognitive goals (such as making gender and gender bias visible or understanding mechanisms of suppression), even if those goals have an explicit socio-political background. What is more, Longino does not propose a general replacement of the Kuhnian values by feminist ones but wants to illustrate the impossibility of one context-independent set of legitimate values. On the one hand, she argues that her feminist values fulfil a cognitive function in promoting specific (feminist) research goals; on the other, that the Kuhnian values are possibly connected with social values, too (cf. Longino 1995; 1996).

The feminist list also starts with empirical adequacy as necessary, but insufficient criterion. It is followed by novelty, which expresses a preference for theories that differ significantly from other accepted theories in the field. This preference is based on the supposition of androcentric tendencies of the research mainstream, as feminist research has been able to discover numerous examples of respective bias (see for example the criticism of the underlying assumptions of the 'man-the-hunter-model' mentioned above). Novelty is contrasted with external coherency, which is interpreted by Longino as perpetuation of the androcentric status quo.

Ontological heterogeneity attributes the same importance to different sorts of entities, rather than announcing one sort the standard version - which, according to Longino, is prone to regard differences as deviants or even deficiencies. Instances of the problematic character of simple ontologies can be found in medical research. For example, before the development of women's health research, studies on coronary heart diseases used to focus exclusively on men, which led to a designation of differing female symptoms as 'atypical' (eventually resulting in a higher female mortality rate) (cf. for example Kolip/Kuhlmann 2005, 141-172; Schiebinger 1999, 107-125; Epstein 2007, especially chapters 3 and 11).

Complexity of relationship is the processual version of ontological heterogeneity and stresses interactions of different factors rather than one-way causalities. An exemplary case can be found in reproductive biology and the consideration of the female egg as passively waiting for its fertilisation by the aggressive sperm, which was superseded by the ascription of a more active role to the egg (cf. for example Martin 1991). This value is justified as guarding against a naturalisation of power relations; moreover, complex models are supposed to be more apt to recognise female contributions. Ontological heterogeneity and complexity of interaction are opposed to an ontological interpretation of simplicity as well as breadth of scope, which are thought to lead to a problematic disregard of indi- 
vidual differences and interactional connections. ${ }^{11}$ Another example of the value of relational complexity is the conflict between linear-hormonal and selectionist explanations of neuro-physiological development and gender-specific behaviour mentioned above. The latter replaces the uni-directional simplicity of the former by an interactionist account, which can be considered as promoting a view of gender-differences as depending on the social context and therefore alterable, rather than supporting social inequalities by a biological grounding.

At last, Longino mentions applicability of research results to current human needs and diffusion of power. The latter can be seen as a specification of the former and indicates for example a preference for less exclusive research programmes in terms of equipment or a focus on prevention instead of on high-end technology in medicine. In opposite to applicability to human needs, fruitfulness is said to be conservative because it ignores the relation of research to social problems.

Whereas Longino considers the last two values as pragmatic criteria relevant to theory pursuit (i.e. as guiding decisions on what theories to work on), the role she ascribes to the other feminist values mirrors that of the traditional cognitive ones. They not only influence the formulation of theories or initial assessments of plausibility but function as criteria in theory choice and thus in decisions on the acceptance or rejection of scientific contents (cf. Longino 1995, $390 ; 1996,42)$. Although neither set of values could be said to promote truthlikeliness, they nevertheless function as indicators of which theories to prefer in the light of alternatives - just not independent of the context of specific research programmes.

\section{Social Objectivity and Local Epistemologies}

Longino does not understand these feminist criteria as cognitive values in any absolute sense, which would replace the Kuhnian values. Rather, she ascribes the same context-dependent status to both lists. Instead of values generally relevant to theory choice decisions, she assumes various sets of values invoked by different communities:

"The normative claim of these values/virtues/heuristics is limited to the community sharing the primary goal. On those who do not share it they have no claim. To expand this point, the alternative values are only binding in those communities sharing a cognitive goal that is advanced by those values. [...] Any set, then, will be only provisional and locally binding." (Longino 2008, 79)

\footnotetext{
11 These oppositions are somewhat at odds with the Kuhnian interpretation of his criteria; he relates simplicity to the unification of results rather than to the reduction of entities in an ontological framework, and scope to the inclusion of unforeseen results rather than to the reduction of explanatory principles and relational complexity, as Longino understands him to. To make the contrast more straightforward, she would need to spell out the connection of her ontological interpretation to the respective ideas about unification and explanation. However, a failure of her oppositions would not per se discredit the idea of feminist cognitive values.
} 
Two problems need to be discussed here. The first is the lack of communityexternal standards of theory assessment. If each community has its own standards serving as basis of the critical process, it is hard to see how to avoid that the gap left open by empirical adequacy is closed by community-specific values. This might generate a miscellany of approaches, standards, and results, without any possibility of consensus-finding exceeding logical consistency and empirical adequacy. Since the overall argumentation starts from the assumption of significant leeway opened up by the underdetermination problem, there would not much be gained.

In addition, the idea of community-specific values in theory choice poses an internal problem for Longino's account. As mentioned before, Longino's notion of social objectivity depends on shared standards of criticism if it is to produce a justified consensus. Her insistence on variable sets of constitutive values for individual communities is tantamount to her suggestion of different local epistemologies (instead of one epistemology valid for the whole of science, cf. Longino 1997; 2002, 184ff.). ${ }^{12}$ I will argue that this is deeply problematic for the conception of social value management as providing the basis for science's epistemic integrity.

Scientific communities on Longino's account are constituted by a common goal (cf. Longino 2002, 176). Such goals, for example to make gender and gender bias visible, are cognitive goals. But the choice of certain cognitive goals can be influenced by non-cognitive values, such as the quest for gender equality. Thus, a shared cognitive goal can be a function of shared social, religious, or moral values. This generates a tension with Longino's demand for criticism from different perspectives within a community (cf. also Lennon 1997, 44ff.). All members of a so defined community will share certain values, which make them pursue the same goal and the derived constitutive values. This seriously diminishes the chance that value-assumptions are made visible by mutual criticism.

The diversity of criticism would therefore have to be accomplished by intercommunity discourse. This generates the question of how such a criticism between different communities can be effective, where each community has its own constitutive values respectively criteria of evaluation. Comparability and shared standards would presume a consensus on specific and often value-laden goals of research, which is neither a probable outcome in a group characterised by diversity, nor intended by Longino's contextual empiricism and its stress on plurality. Yet without common standards, the outcome might be a methodological incommensurability of research done by different communities.

Consequently, the local epistemologies Longino suggests pose a problem in connection with her notion of social objectivity. Neither scientific sub-communities constituted by common values and goals nor meta-communities divided into sub-communities with different evaluation standards meet the conditions Longino invokes for objectivity. The first situation violates the condition of

\footnotetext{
12 Such community-dependent epistemologies are constituted by methodological as well as substantive commitments. Since substantive assumptions are supposed to be controlled by the procedure of mutual criticism, which depends on methodological criteria such as the values for theory choice, these will be discussed as equivalent to Longino's public standards here.
} 
diverse criticism from all possible sides (4), while the second excludes the possibility of transformative criticism (2) due to a lack of shared standards (3). Without commonly binding criteria, criticism can always be silenced by declaring it as irrelevant according to one's own standards. Probably, at least where value-assumptions do play a role, this would lead to a situation where not a single theory could pass the (inter-community) process of criticism and transformation. The feminists would have their theory, the Marxists another one, etc. In the end, Longino's allowance of value-influences would lead to a situation of multiple and incommensurable approaches, and her own goal of making value-laden assumptions assessable would not be reached.

Longino answers this problem by proposing tolerance and interaction between communities with different sets of constitutive values (cf. Longino 2008, 82). This would solve the problem of the internal lack of diversity, but still calls for some common ground of different communities. Longino assumes a partial overlap of different sets of values: "Nor is criticism limited to intracommunity discourse. The areas of overlap or intersection make possible critical interaction among as well as within communities." (82) Against the background of her remarks about different sets of values yielding incompatible results, this raises the question of how such an overlap can be explained and what guarantees its sufficiency for effective communication. Concerning her list of feminist values, Longino on the contrary underlines their opposition to the traditional set of Kuhn. The only overlap lies in the anyway necessary criteria of empirical adequacy and internal consistency. Since the discussion on values in theory choice starts from the premise that these two criteria are insufficient to evaluate the epistemic quality of a theory, they are also insufficient as a basis for the required inter-community interaction. Communication about and effective criticism of value assumptions would be rendered impossible- - but this is exactly what social objectivity wants to assure.

\section{Proceduralism and the Strive for Consensus}

In a recent article, Longino puts forward a more modest claim regarding her list of feminist values. She no longer presents them as criteria of theory choice, but as merely heuristic means, that is, as guiding the development of theories. While she always considered the feminist or traditional values as relevant in different research stages, she here reduces their normative function to questions of theory formulation and pursuit, instead of treating them as criteria for the acceptance or rejection of theories. Nevertheless, she sticks to the edge of her argumentation: while she does not claim her feminist values to be appropriate for any evaluation of validity, she also denies this status to the traditional cognitive values: "The feminist and the traditional virtues are on a par, epistemologically. Both have heuristic but not probative power." (74)

To regard all values but the necessary ones as merely heuristic in nature could well be a maintainable empiricist position. But it is not a consistent position for Longino, who proceeds on the assumption of an underdetermination of scientific 
beliefs by data, in so far as these beliefs aim at a theoretical understanding of phenomena instead of pure enumeration. If one acknowledges the possibility of empirically underdetermined theory choice decisions, this creates the problem of which non-empirical criteria should be adopted. To deny the existence of any sustainable criteria of choice leads to a lack of public standards on which to base the criticism facing such situations - a basis the existence of which is essential to Longino's account of social objectivity. Therefore, it does not seem a good move to consider the discussed values as relevant only to heuristics, not to theory choice decisions. The reason for this restriction was the lack of probative power Longino ascribes to the traditional as well as to the cognitive ones. It is indeed notoriously difficult to identify a group of values that enhance the truthlikeliness or probability of theories, as has been discussed above. But even if we grant this impossibility to generally attribute probative power to a certain set of values, this does not rule out any admissible role for values in theory choice.

Consider how Longino came to identify her list of feminist values in the first place. She did not single out properties of theories by their contribution to the latter's truth or to other measures of general epistemic quality. Rather, she identified properties operating as values in feminist research for advancing the specific cognitive goal of understanding gender-related issues. As she repeatedly states herself, it is this contribution that makes the values feminist, not any intrinsic features or relations to feminism. What promotes feminist cognitive goals has to be understood as contingent result of a learning process. The same can be said about the traditional values: they are the result of an actually much longer learning process. Even if they cannot be said to enhance the truth of theories, they may be seen as contributing to the epistemic quality of specific theories relative to the research goals pursued. In the absence of any absolute way to distinguish certain values as cognitive, a process of learning by doing seems the best we can hope for. Yet as long as it is possible to identify improving degrees of realisation of the set goals (as Longino claims for her feminist research cases), there is still a pathway to establish shared non-empirical standardseven if no clear distinction between cognitive and non-cognitive values can be presumed. This means that it is to a certain degree possible to support values for theory choice on empirical grounds, i.e. by comparing the success of theories exhibiting them in relation to the goals pursued. However, so far no single set of values could be empirically demonstrated as superior (and it seems unlikely that this will ever happen, if even the traditional values often conflict with each other; see above on 'Kuhn-underdetermination'). Furthermore, this does not warrant value-freedom of the respective criteria, if one accepts the possible value-ladenness of the research goals they are thought to promote.

It is neither a good choice to refuse the possibility of non-empirical criteria of theory choice nor to make them exclusively dependent on individual communities' goals in a way that leads to local epistemologies and methodological incommensurability. The local and provisional nature of cognitive values must not preclude inter-community debate, but has to be accompanied by the demand to defend them to non-community members in relation to one's research goals; and where different goals and standards lead to incompatible results, they 
themselves need to be exposed to the process of mutual criticism from diverse perspectives. As Longino puts it herself:

"The satisfaction of goals of inquiry is not ascertained privately, but by evaluation with respect to shared values and standards. This evaluation may be performed by anyone, not just by members of the community sharing al standards. Furthermore, standards are not a static set, but may themselves be criticized and transformed, in reference to other standards, goals, or values, held temporarily constant. Indeed, the presupposition of reliance on such standards is that they have survived similar critical scrutiny." (Longino 1996, $40)^{13}$

In the end, Longino's conception of objectivity requires the emphasis on the social character of enquiry to be accompanied by one on the procedural nature of social objectivity. ${ }^{14}$ This proceduralism maintains on three levels: first, the discussion of scientific results from diverse perspectives; second, the debate on appropriate standards of theory choice; and third, the deliberation on appropriate research goals. On all levels, it is possible that disputes remain unresolved. But what makes social objectivity possible is that the participants aim at a resolution by means of extensive and multi-perspectival criticism. In order to assure this effort of multi-level debate, the social conception of objectivity must include the normative ideal of an inter-community consensus. Even if it might not always be achievable, the strive for consensus is what saves social objectivity from collapsing into the problematic epistemological pluralism Longino's own approach allows for. To part the ideas of value-freedom and objectivity, the attention to the social context of science must thus be accompanied by a thoroughly procedural epistemology, to which not the success but the constant effort to overcome any incommensurable local epistemologies is essential.

\section{Concluding Remarks}

I have argued that it is neither necessary nor recommendable to consider the traditional and the feminist cognitive values merely as heuristics. However, Longino has an important point in highlighting their heuristic function. According to her, such values influence earlier stages of theory development like the choice of problems, the selection of data considered relevant, the choice of methods, or initial assessments of plausibility. These values also form an important part of the background assumptions that mediate between theory and evidence. They frame research problems in specific ways by influencing what aspects of a problem are considered significant and which will be disregarded. Underdetermination of theory by evidence presumed, non-empirical values have

\footnotetext{
13 For an account of such a multi-level deliberation without any Archimedean basis, cf. also Laudan 1984 who identifies relations of affirmation between aims, methodological rules, and results of enquiry.

14 Concerning the merits of a procedural account of objectivity, cf. also Wilholt 2009.
} 
a role to play in theory choice decisions; but by shaping the research in earlier stages, they also decisively influence these decisions in so far as they affect what alternatives there will be to choose from (cf. also Ohkrulik 1998). Whether those alternatives might all incorporate the same value-laden assumptions is in turn again a question of social objectivity. Here, the ideal of integrating as diverse perspectives and values as possible into the scientific community comes to bear again by encouraging pluralism with regards to the sort of approaches pursued. Before settling on any theory choices, it seems uncontroversial that this would in the best case be done in the light of numerous, significantly different alternatives, which may highlight the blind spots of each other.

In addition to Longino's criticism of the value-freedom of justification, this signifies the contexts of discovery and pursuit as an important topic for social epistemology. Such heuristic influences shape what theory choice decisions we will eventually confront and what evidence will be available, which is why they are epistemologically relevant. At the same time, the social dimension of these heuristics calls for attention; their relation to specific, possibly value-laden research goals suggests that 'discoveries', traditionally treated as rather coincidental in philosophy of science, bear a more systematic connection to the social background of science. Value-influences are not only of normative interest when it comes to the final evaluation of epistemic acceptability, but rather require a permanent monitoring. ${ }^{15}$

To sum up, the social and procedural conception of objectivity, which does not ground on the value-freedom of science but rather on the reflection and open discussion of the values at play, can provide a coherent and fruitful account of how to deal with value-influences - but only if it includes the normative requirement to strive for inter-community consensus.

\section{Bibliography}

Carrier, M. (2008), The Aim and Structure of Methodological Theory, in: Soler, L./H. Sankey/P. Hoyningen-Huene (eds.), Rethinking Scientific Change and Theory Comparison: Stabilities, Ruptures, Incommensurabilities?, Dordrecht, 273-290

Epstein, S. (2007), Inclusion: The Politics of Difference in Medical Research, Chicago

Kolip, P./E. Kuhlmann (2005), Gender und Public Health. Grundlegende Orientierungen für Forschung, Praxis und Politik, Weinheim-München

Kuhn, T. S. (1977), Objectivity, Value Judgement, and Theory Choice, in: The Essential Tension: Selected Studies in Scientific Tradition and Change, Chicago, 320-339

Kitcher, P. (2001), Science, Truth, and Democracy, New York

Laudan, L. (1984), Science and Values: The Aims of Science and their Role in Scientific Debate, Berkeley

- (2004), The Epistemic, the Cognitive, and the Social, in: Machamer, P./G. Wolters (eds.), Science, Values, and Objectivity, Pittsburgh, 14-23

\footnotetext{
15 The permanent nature of this task moreover suggests that the inclusion of diverse values and perspectives via an internal democratisation of the scientific community is superior to Kitcher's proposal of a participation of societal representatives at the single 'external' point of decision-making on the direction of research (cf. footnote 1).
} 
Lennon, K. (1997), Feminist Epistemology as Local Epistemology, Part II, in: The Aristotelian Society (Supplementary Volume LXXI), 37-54

Longino, H. E. (1990), Science as Social Knowledge: Values and Objectivity in Scientific Enquiry, Princeton

- (1995), Gender, Politics, and the Theoretical Virtues, in: Synthese 104, 383-397

- (1996), Cognitive and Non-Cognitive Values in Science: Rethinking the Dichotomy, in: Nelson, L. H./J. Nelson (eds.), Feminism, Science, and the Philosophy of Science, Dordrecht, 39-58

- (1997), Feminist Epistemology as Local Epistemology, Part I, in: The Aristotelian Society (Supplementary Volume LXXI), 19-35

- (2002), The Fate of Knowledge, Princeton

- (2008), Values, Heuristics, and the Politics of Knowledge, in: Carrier, M./D. Howard/J. Kourany (eds.), The Challenge of the Social and the Pressure of Practice: Science and Values Revisited, Pittsburgh, 68-86

Martin, E. (1991), The Egg and the Sperm: How Science Has Constructed a Romance Based on Stereotypical Male-Female Roles, in: Signs 16, 485-501

McMullin, E. (1983), Values in Science, in: Asquith, P. D./T. Nickles (eds.), PSA 1982 Volume II, Proceedings of the 1982 Biennial Meeting of the Philosophy of Science Association: Symposia, East Lansing, 3-28

Ohkrulik, K. (1998), Gender and the Biological Sciences, in: Cover, J. A./M. Curd (eds.), Philosophy of Science: The Central Issues, New York, 192-208

Ruphy, S. (2006), 'Empiricism All the Way Down': A Defence of the Value-Neutrality of Science in Response to Helen Longino's Contextual Empiricism, in: Perspectives on Science 14, 189-214

Schiebinger, L. (1999), Has Feminism Changed Science?, Cambridge/MA

Smith, T. (2004), 'Social' Objectivity and the Objectivity of Values, in: Machamer, P./G. Wolters (eds.), Science, Values, and Objectivity, Pittsburgh, 143-171

Wilholt, T. (2009), Die Objektivität der Wissenschaften als soziales Phänomen, in: Analyse \& Kritik 31, 261-273 